\title{
Nd-Fe-B thick-film magnets prepared by high laser energy density
}

\author{
M. Nakano ${ }^{1}$, K. Fujiyama ${ }^{1}$, T. Yanai ${ }^{1}$, M. Itakura², and H. Fukunaga ${ }^{1}$, Member, IEEE \\ ${ }^{1}$ Graduate School of Engineering, Nagasaki University, Nagasaki 852-8521, Japan \\ ${ }^{2}$ Interdisciplinary Graduate School of Engineering Sciences, Kyusyu University, Fukuoka, Japan
}

An observation of microstructure revealed that a laser-irradiated Nd-Fe-B target under the laser energy density (LED) above $10 \mathrm{~J} / \mathrm{cm}^{2}$ enabled us to prepare isotropic nano-composite thick-film magnets with good magnetic properties due to a dispersed $\alpha$-Fe $+\mathrm{Nd}$-Fe-B structure. The formation of the structure is attributed to the etching process of a target during a deposition. Moreover, the control of composition in the nano-composite film enhanced $(\mathrm{BH})_{\max }$ value up to approximately $130 \mathrm{~kJ} / \mathrm{m}^{3}$.

Index Terms-Nd-Fe-B, PLD (Pulsed Laser Deposition), laser energy density, droplet

\section{INTRODUCTION}

$\mathrm{M}$ any researchers have demonstrated miniaturized devices comprising anisotropic Nd-Fe-B film magnets.[1]-[3] Recently, our group reported isotropic $\mathrm{Nd}-\mathrm{Fe}-\mathrm{B}+\alpha-\mathrm{Fe}$ nanocomposite film magnets prepared by a PLD (Pulsed Laser Deposition) method using the small spot size of laser beam less than $1 \mathrm{~mm}$ together with LED (Laser Energy Density) $\geqq 10$ $\mathrm{J} / \mathrm{cm}^{2}$ in order to apply the films to a multi-polarly magnetized rotor for a miniaturized cylindrical motor.[4,5] The deposition rate of a previously-reported process using the large spot size of several mm by taking account of a defocused laser beam on the surface of a target (LED $\leqq 1 \mathrm{~J} / \mathrm{cm}^{2}$ ) reached $90 \mu \mathrm{m} / \mathrm{h}[6]$ and the film thickness increased up to $1300 \mu \mathrm{m}$.[7] On the other hand, the above-mentioned process using LED $\geqq 10 \mathrm{~J} / \mathrm{cm}^{2}$ had a relatively low deposition rate of $20-40 \mu \mathrm{m} / \mathrm{h}$ and the good magnetic properties of $\mathrm{Br} \geqq 0.9 \mathrm{~T}$, Hc $\geqq 300 \mathrm{kA} / \mathrm{m}$, and $(\mathrm{BH})_{\max } \geqq 80 \mathrm{~kJ} / \mathrm{m}^{3}$, respectively, could be confirmed only within the thickness range from 10 to $20 \mu \mathrm{m}$. [5]

In this study, an observation on the microstructure of a NdFe-B nano-composite thick-film prepared by LED above 10 $\mathrm{J} / \mathrm{cm}^{2}$ was carried out to examine the origin for obtaining good magnetic properties. In order to investigate the process to form the above-mentioned microstructure, the relationship between magnetic properties and deposition time was also studied. Furthermore, we succeeded in an enhancement in $(\mathrm{BH})_{\max }$ by taking account of the composition for the nano-composite films.

\section{EXPERIMENTAL PROCEDURE}

A rotated target with the composition of $\mathrm{Nd}_{2.4} \mathrm{Fe}_{14} \mathrm{~B}$ was ablated by an Nd-YAG pulse laser (wave length $=355 \mathrm{~nm}$ ). The films deposited on each Ta substrate were fabricated in the vacuum atmosphere of $10^{-5} \mathrm{~Pa}$ [8]. A laser energy density (LED) varied by a spot size of laser beam which could be controlled by moving the distance between a focal lens and a target intentionally. The range of LED above $10 \mathrm{~J} / \mathrm{cm}^{2}$ was used under fixing the laser power of $4 \mathrm{~W}$ which was measured with a power meter in front of the entrance lens of a chamber. The deposition rate became from 20 to $40 \mu \mathrm{m} / \mathrm{h}$ by using the distance of $10 \mathrm{~mm}$ between a target and a substrate. All the asdeposited films thicker than $10 \mu \mathrm{m}$ were crystallized by a pulse annealing (PA) method in the vacuum atmosphere of $2-5 \times 10^{-5}$ Pa. [9]

The magnetic properties of the annealed samples were measured with a vibrating sample magnetometer (VSM) under applied maximum magnetic field of $2.5 \mathrm{~T}$ after magnetization under a pulsed magnetic field of $7 \mathrm{~T}$. In the results, in-plane magnetic properties were only shown because all the films had isotropic magnetic properties. The film thickness was measured with a micrometer and the composition of each film was analyzed with an energy dispersive X-ray spectrometry (EDX). The microstructure was observed with a Transmission Electron Microscope (TEM).

\section{RESULTS AND DISCUSSION}

A. Magnetic properties and Microstructure of $\mathrm{Nd}-\mathrm{Fe}-\mathrm{B}$ thick-film magnets prepare by $L E D \geqq 10 \mathrm{~J} / \mathrm{cm}^{2}$

Figure 1 shows $(\mathrm{BH})_{\max }$ values of Nd-Fe-B thick-film magnets prepared by using LED $\leqq 1 \mathrm{~J} / \mathrm{cm}^{2}$ and LED $\geqq 10 \mathrm{~J} / \mathrm{cm}^{2}$, respectively. Although the $\mathrm{Nd}$ contents of each film were almost the same range of between 8 and 10 at \%., the average $(\mathrm{BH})_{\max }$ value of the samples prepared by high LED was higher than that of low LED-made ones by approximately $20 \mathrm{~kJ} / \mathrm{m}^{3}$. In order to investigate the mechanism for obtaining superior $(\mathrm{BH})_{\max }$ due to the increase in LED as shown in Fig.1, the microstructure of a sample prepared by LED $\geqq 10 \mathrm{~J} / \mathrm{cm}^{2}$ was observed. The sample was prepared by using the deposition time of $30 \mathrm{~min}$. As displayed in Fig. 2, a dispersed $\alpha-\mathrm{Fe}+\mathrm{Nd}-$ Fe-B structure could be obtained and it was confirmed that the average diameter of $\alpha$-Fe grains was approximately $20 \mathrm{~nm}$,

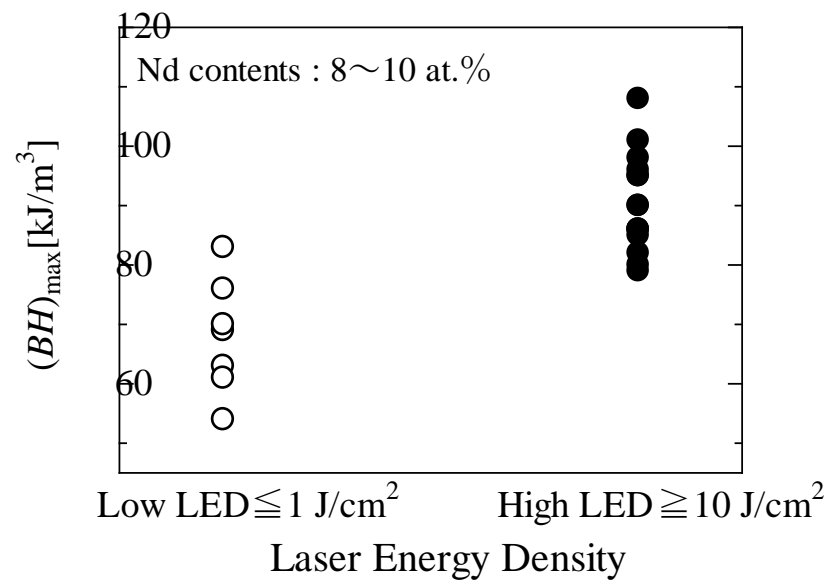

Fig. $1(\mathrm{BH})_{\max }$ of Nd-Fe-B thick-film magnets prepared by different values of LED. The Nd content range of each film prepared by LED less than $1 \mathrm{~J} / \mathrm{cm}^{2}$ and higher than $10 \mathrm{~J} / \mathrm{cm}^{2}$, respectively, was almost the same as from 8 to 10 at \%., however the value of $(B H)_{\max }$ for the samples prepared by high LED was superior. 
which is one of optimum conditions for a nano-composite magnet considering an exchange interaction length. Namely, usage of LED above $10 \mathrm{~J} / \mathrm{cm}^{2}$ enabled us to fabricate an isotropic nano-composite thick-film magnet with good magnetic properties due to the ideal microstructure.

In order to investigate the mechanism to form the microstructure, the relationship between various properties and deposition time was examined. The extension of continuous deposition time up to 180 min. was carried out under LED $\geqq$ $10 \mathrm{~J} / \mathrm{cm}^{2}$ as seen in Fig. 3. The thickness increased linearly up to $120 \mathrm{~min}$. as the deposition time prolonged and the drastic enlargement in the thickness at the deposition time of $150 \mathrm{~min}$. could be observed. It was found that the phenomenon was attributed to the large amount of emitted droplets from a target. (see Fig. 4) In the case of LED $\leqq 1 \mathrm{~J} / \mathrm{cm}^{2}$, the use of droplets was a key technology to obtain deposition time became over 10 h ( Total thickness : $1300 \mu \mathrm{m}$ ).[7] On the other hand, as a sample was fabricated by the maximum deposition rate of approximately $90 \mu \mathrm{m} / \mathrm{h}[6]$ and the deposition rate was almost the same even if the using LED $\geqq 10 \mathrm{~J} / \mathrm{cm}^{2}$, the droplets were explosively emitted due to the progress of erosion a Nd-Fe-B target after a continuously long deposition up to $180 \mathrm{~min}$ (see Fig. 5).

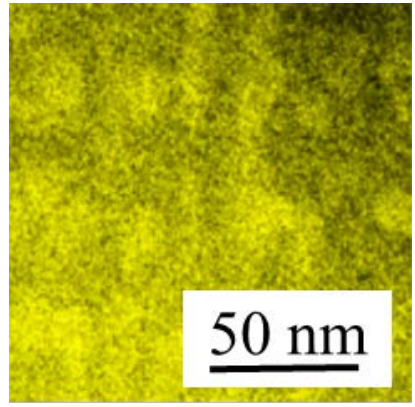

(a) TEM observation

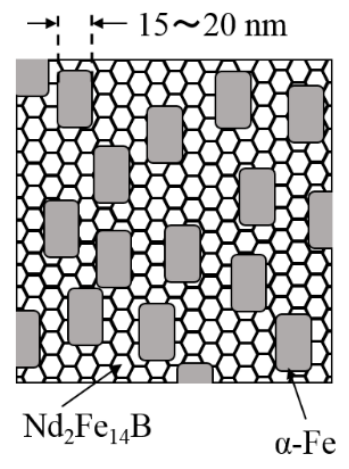

(b) Schematic diagram of Fig. 2 (a)
Fig. 2 Photograph and schematic diagram of microstructure for an isotropic nano-composite thick-film magnet with a dispersed $\alpha$-Fe $+\mathrm{Nd}-\mathrm{Fe}-\mathrm{B}$ structure. The sample was prepared by using LED $\geqq 10 \mathrm{~J} / \mathrm{cm}^{2}$ under the deposition time of $30 \mathrm{~min}$.

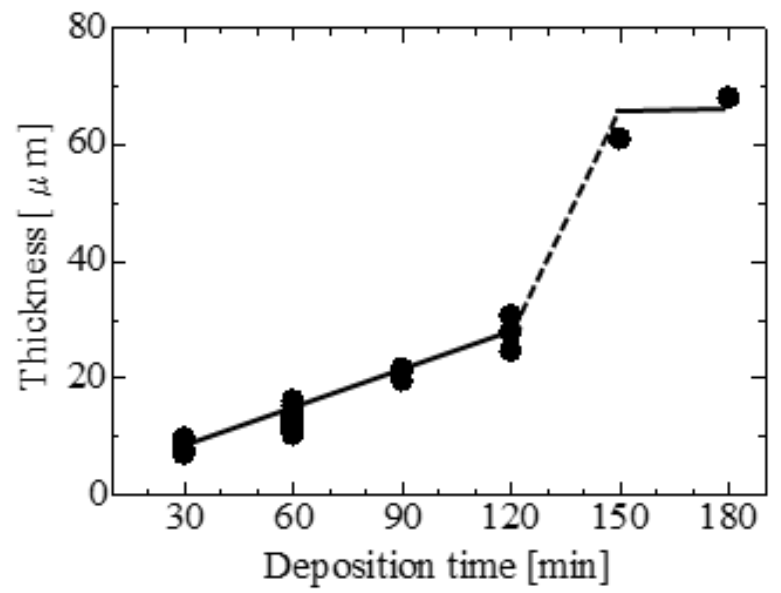

Fig. 3 Thickness of film magnets prepared by using LED $\geqq 10 \mathrm{~J} / \mathrm{cm}^{2}$ as a function of deposition time. The drastic increase in the thickness occurred at the deposition time of $150 \mathrm{~min}$.
In the case of deposition time of 180 min., the target was roughly etched and resultantly large amounts of droplets were emitted. Figure 6 shows the magnetic properties of the films plotted in Fig. 3. The average values of remanence and coercivity showed approximately $1.0 \mathrm{~T}$ and $350 \mathrm{kA} / \mathrm{m}$, respectively, up to $120 \mathrm{~min}$., and the remanence values extremely dropped under the prolongation of deposition time. The relative large variation of the remanence of the film deposited under 30min together with the coercivity of the film deposited under $60 \mathrm{~min}$. is considered to be attributed to the fluctuation of Nd contents in each film as shown in Fig. 7. In addition, the measurement in the composition of surface area suggests that almost droplets had Nd-rich composition compared with stoichiometric one. We also considered that the erosion of a target due to the prorogation in the deposition time leaded to increase the size and/or numbers of droplets. Since the $\mathrm{Nd}$ content of each droplet showed almost the same value compared to that of a $\mathrm{Nd}_{2.6} \mathrm{Fe}_{14} \mathrm{~B}$ target, it was, therefore, considered that the emitting mechanism of the deposition time above $150 \mathrm{~min}$. became similar to that of LED $\leqq 1 \mathrm{~J} / \mathrm{cm}^{2}$. These results suggest that usage of a small spot size of a laser beam (LED $\geqq 10 \mathrm{~J} / \mathrm{cm}^{2}$ ) within an optimum deposition time enabled us to obtain isotropic nano-composite thick-film magnets with good magnetic properties due to the-above mentioned microstructure.

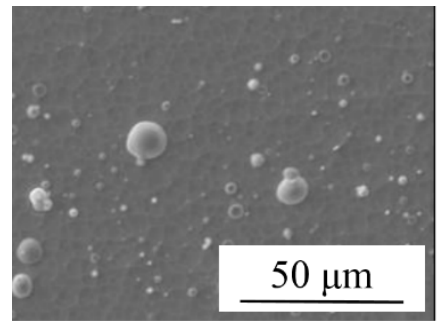

(a) $60 \mathrm{~min}$.

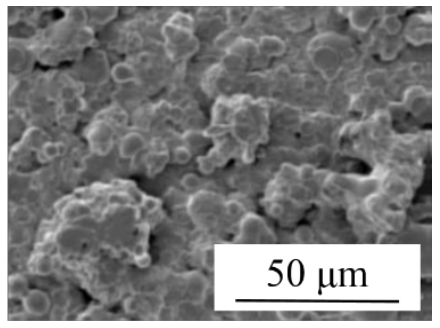

(b)180 min.
Fig. 4 Surface morphology of film magnets prepared by using LED $\geqq 10 \mathrm{~J} / \mathrm{cm}^{2}$ at the deposition times of 60 and 180 min. respectively. A large amounts of emitted droplets from a target could be observed in the sample deposited for $180 \mathrm{~min}$.

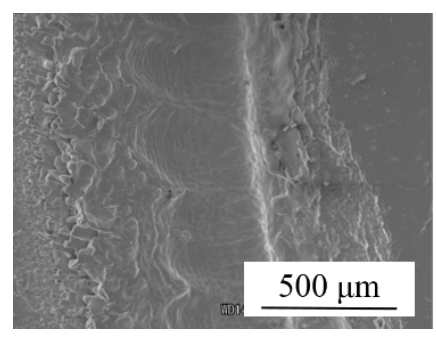

(a) 60 min.

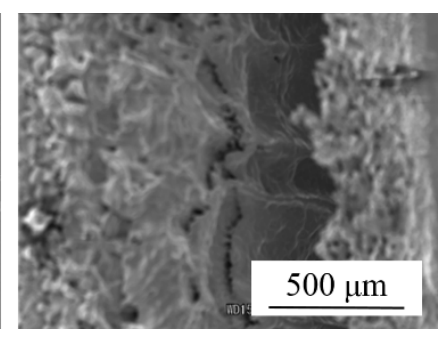

(b) $180 \mathrm{~min}$.
Fig. 5 Surface observation of each target ablated by LED $\leqq 10 \mathrm{~J} / \mathrm{cm}^{2}$ for 60 and $180 \mathrm{~min}$., respectively. The numbers and/or size of emitted droplets is relatively small because the target was delicately etched. 


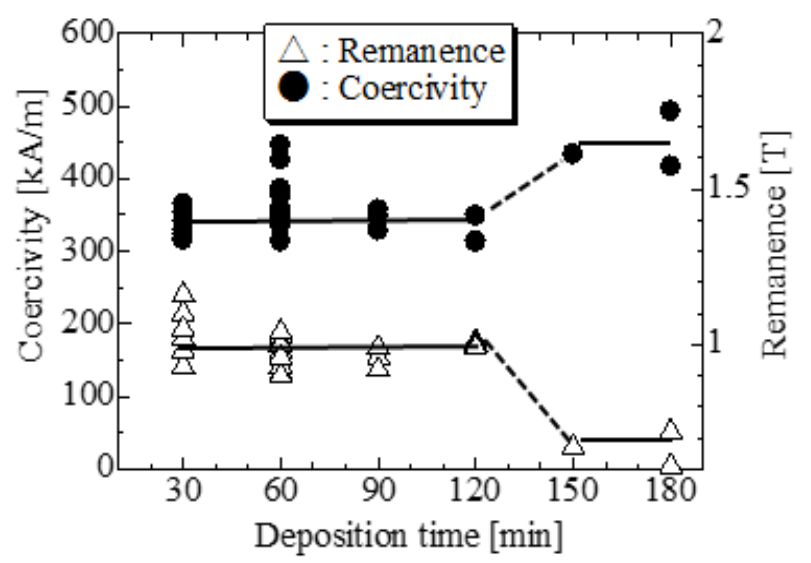

Fig. 6 Magnetic properties for Nd-Fe-B thick film magnets prepared by using LED $\geqq 10 \mathrm{~J} / \mathrm{cm}^{2}$ as a function of deposition time. Remanence and coercivity showed constant values in the deposition time range from 30 to $120 \mathrm{~min}$.

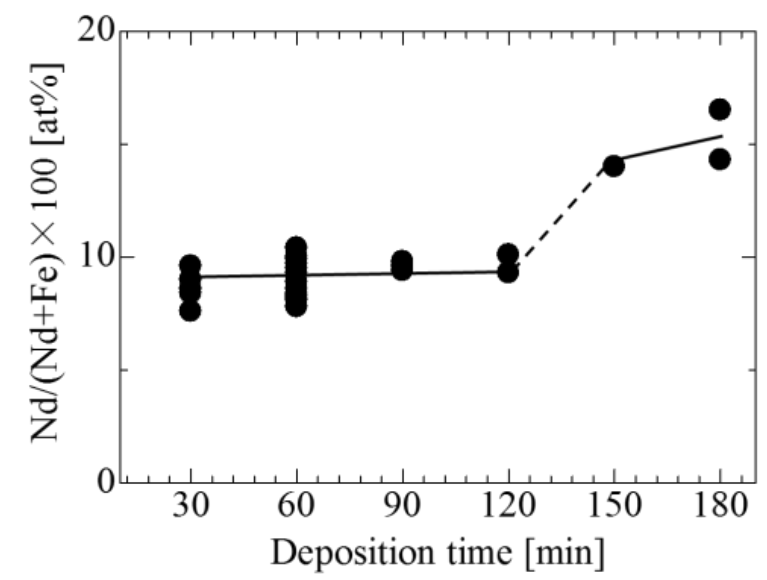

Fig.7 Nd contents of film magnets prepared by using LED $\geqq 10 \mathrm{~J} / \mathrm{cm}^{2}$ as a function of deposition time. The amount of Nd extremely increased in the samples deposited for 150 and $180 \mathrm{~min}$. due to the increase in the numbers and/or size of droplets.

\section{B. Improvement in magnetic properties of Nd-Fe-B thick- film magnets prepare by $L E D \geqq 10 \mathrm{~J} / \mathrm{cm}^{2}$}

Although the $(B H)_{\max }$ of a film prepared by LED $\geqq 10 \mathrm{~J} / \mathrm{cm}^{2}$ reached up to approximately $110 \mathrm{~kJ} / \mathrm{m}^{3}$ as shown in Fig. 1, the value was inferior to those of isotropic RE (Nd or Pr)-Fe-B $/ \alpha$ Fe nano-composite ribbons with $(B H)_{\max }$ above $130 \mathrm{~kJ} / \mathrm{m}^{3}$ [4][10] In order to improve the magnetic properties, an control of composition in the above-mentioned films was carried out by increasing the $\mathrm{Nd}$ amount of a Nd-Fe-B target as displayed in Fig. 8. It was clarified that an increase in $\mathrm{Nd}$ content in a film up to 11.5 at.\% enabled us to enhance the value of $(B H)_{\max }$ by approximately $20 \mathrm{~kJ} / \mathrm{m}^{3}$ compared with those of samples with the Nd contents range from 8 to 10 at.\% (see Fig. 1). Furthermore, a M-H loop of a sample with the $(\mathrm{BH})_{\max }$ of 128 $\mathrm{kJ} / \mathrm{m}^{3}$ was shown in Fig. 9.

It was clarified that the improvement in $(\mathrm{BH})_{\max }$ by controlling the film composition in PLD-fabricated nano-composite thickfilm magnets prepared by LED $\geqq 10 \mathrm{~J} / \mathrm{cm}^{2}$.

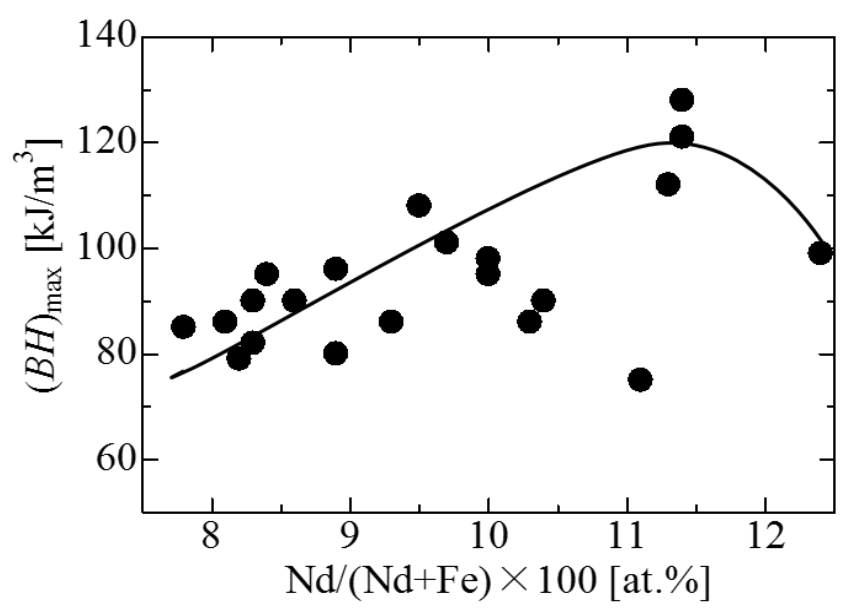

Fig. $8(B H)_{\max }$ of Nd-Fe-B thick-film magnets prepared by $L E D \geqq 10 \mathrm{~J} / \mathrm{cm}^{2}$ as function of $\mathrm{Nd}$ contents. The value of $(\mathrm{BH})_{\max }$ increased with increasing $\mathrm{Nd}$ contents up to approximately 11.5 at. \%.

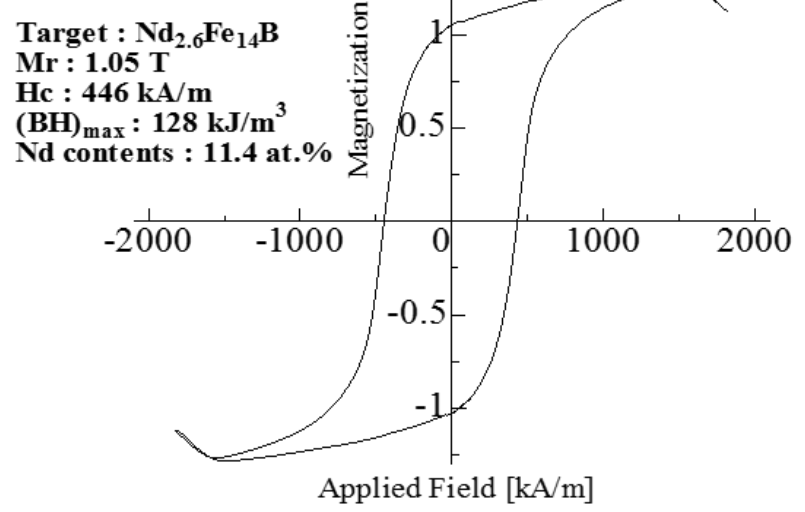

Fig. 9 M-H loop of a sample with the Nd content of 11.4 at. \% seen in Fig. 8. The sample with $(B H)_{\max }$ of $128 \mathrm{~kJ} / \mathrm{m}^{3}$ could be obtained by using a $\mathrm{Nd}_{2.6} \mathrm{Fe}_{14} \mathrm{~B}$ target ablated at $\mathrm{LED} \geqq 10 \mathrm{~J} / \mathrm{cm}^{2}$.

\section{CONCLUSION}

In this study, we fabricated isotropic nano-composite thickfilm magnets by using a PLD method with high laser energy density (LED) above $10 \mathrm{~J} / \mathrm{cm}^{2}$. The obtained results are summarized as follows;

(1) A nano-composite film with dispersed $\alpha$-Fe $+\mathrm{Nd}$-Fe-B structure could be formed and the average diameter of $\alpha$ Fe grains was approximately $20 \mathrm{~nm}$.

(2) Usage of a small spot size of a laser beam within an optimum deposition time enabled us to form the-above mentioned microstructure.

(3) The control of composition in the above-mentioned nanocomposite film was effective to enhance the $(\mathrm{BH})_{\max }$ value up to approximately $130 \mathrm{~kJ} / \mathrm{m}^{3}$. 


\section{REFERENCES}

[1] P. McGuiness, D. Jezersek, S. Kobe, B. Markoh, S. Spaic, and B. Saje, "100- $\mu$ m-thick Nd-Fe-B magnets for MEMS applications produced via a low-temperature sintering route”, J. Magn. Magn. Mater. 305, 177181(2006).

[2] A. Walther, C. Marcoux, B. Desloges, R. Grechishkin, D. Givord, N. M. Dempsey, "Micro-patterning of $\mathrm{NdFeB}$ and SmCo magnet films for integration into micro-electro-mechanical-systems”, J. Magn. Magn. Mater. 321, 590-594(2009).

[3] R. Fujiwara, T. Shinshi, and M. Uehara, "Positioning Characteristics of a MEMS Linear Motor Utilizing a Thin Film Permanent Magnet and DLC Coating”, Int. J. of Automation Technology, 7, 148-155(2013).

[4] F. Yamashita, S. Nishimura, O. Kobayashi, M. Itoh, M. Nakano, H. Fukunaga and K. Ishiyama, "Enhancement in magnetic torque of cylindrical micro rotor by usage of directly consolidated $\alpha-\mathrm{Fe} / \mathrm{Pr}_{2} \mathrm{Fe}_{14} \mathrm{~B}-$ based nano-composite thick-films", J. Appl. Phys. 109, 07A712-13(2011).

[5] M. Nakano, K. Motomura, T. Yanai, and H. Fukunaga, "Nano-composite thick film magnets with $\mathrm{Nd}-\mathrm{Fe}-\mathrm{B}+\alpha-\mathrm{Fe}$ phases prepared under high laser energy density”, IEEE Trans. Magn. 50, 2101404-1-4(2014).

[6] M. Nakano, S. Sato, F.Yamashita, T. Honda, J. Yamasaki, K. Ishiyama, M. Itakura, J. Fidler, T.Yanai and H. Fukunaga, "Review of Fabrication and Characterization of Nd-Fe-B Thick Films for Magnetic Machines", IEEE Trans. Magn. 43, 2672-2676(2007).

[7] M. Nakano, T. Honda, J. Yamasaki, S. Sato, F. Yamashita, J. Fidler and H. Fukunaga, "Increase in thickness of PLD-made Nd-Fe-B film magnets and a new application", Sensor Letters, 5, 48-50(2007).

[8] M. Nakano, S. Tutumi, H. Fukunaga, "Preparation of Nd-Fe-B Thin Film Magnets with High Coercivity using Laser Ablation Technique”, IEEE Trans. Magn. 37, 2573-2575(2001).

[9] H. Fukunaga, K. Tokunaga, and J. M. Song, "Improvement in coercivity by high-speed crystallization for PrFeB-Based nanocomposite magnets", IEEE Trans. Magn. 38, 2970-2972(2002).

[10] A. Inoue, A. Takeuchi, A. Makino and T. Masumoto, "Hard Magnetic Properties of Nanocrystalline Fe-Rich Fe-Nd-B Alloys Prepared by Partial Crystallization of Amorphous Phase”, Mater. Trans. JIM, 36, 962971(1995). 